University of Nebraska - Lincoln

DigitalCommons@University of Nebraska - Lincoln

Faculty Publications: Department of

Entomology

Entomology, Department of

June 2003

\title{
Larval distribution and survival of second generation European corn borer, Ostrinia nubilalis (H.ubner) (Lepidoptera: Crambidae) on Event 176 Bt Corn
}

\author{
Amelia C. Zoerb \\ University of Nebraska-Lincoln \\ Terrence A. Spencer \\ University of Nebraska-Lincoln, tspencer1@unl.edu \\ Richard L. Hellmich \\ lowa State University, Ames, IA \\ Robert J. Wright \\ University of Nebraska-Lincoln, rwright2@unl.edu \\ Blair D. Siegfried \\ University of Nebraska-Lincoln, bsiegfried1@ufl.edu
}

Follow this and additional works at: https://digitalcommons.unl.edu/entomologyfacpub

Part of the Entomology Commons

Zoerb, Amelia C.; Spencer, Terrence A.; Hellmich, Richard L.; Wright, Robert J.; and Siegfried, Blair D., "Larval distribution and survival of second generation European corn borer, Ostrinia nubilalis (H.ubner) (Lepidoptera: Crambidae) on Event 176 Bt Corn" (2003). Faculty Publications: Department of Entomology. 9.

https://digitalcommons.unl.edu/entomologyfacpub/9

This Article is brought to you for free and open access by the Entomology, Department of at DigitalCommons@University of Nebraska - Lincoln. It has been accepted for inclusion in Faculty Publications: Department of Entomology by an authorized administrator of DigitalCommons@University of Nebraska - Lincoln. 


\title{
Larval distribution and survival of second generation European corn borer, Ostrinia nubilalis (Hübner) (Lepidoptera: Crambidae) on Event 176 Bt Corn
}

\author{
Amelia C. Zoerb ${ }^{\mathrm{a}}$, Terence Spencer ${ }^{\mathrm{a}}$, Richard L. Hellmich ${ }^{\mathrm{b}}$, Robert J. Wright ${ }^{\mathrm{c}}$, \\ Blair D. Siegfried ${ }^{\mathrm{a}, *}$ \\ ${ }^{a}$ Department of Entomology, University of Nebraska-Lincoln, 202 Plant Industry Building, Lincoln, NE 68583-0816, USA \\ ${ }^{\mathrm{b}}$ USDA-ARS, Corn Insects and Crop Genetics Research Unit, Genetics Laboratory, clo Insectary, Iowa State University, Ames, IA 50011, USA \\ ${ }^{\mathrm{c}}$ South Central Research and Extension Center, University of Nebraska-Lincoln, Clay Center, NE 68933, USA
}

Received 22 February 2002; received in revised form 29 July 2002; accepted 31 July 2002

\begin{abstract}
European corn borer Ostrinia nubilalis Hübner (Lepidoptera: Crambidae) larvae that have completed development on Event 176 Bt corn hybids have either survived exposure to sublethal doses of Cry1 Ab Bt toxin or exploited plant tissues that do not express the toxin. To evaluate the impact of such exposure on larval establishment and survival, Event 176 plants with and without tassels and a non-Bt isoline were infested with $O$. nubilalis egg masses during anthesis. On the non-Bt plants, larval establishment occurred primarily on pollen collecting in the leaf axils, silks and ears. In contrast, almost no larvae were recovered from leaf axils of the Bt treatments and at least 50\% fewer larvae were recovered from the silks and ears during the first 2 weeks after infestation relative to the non-Bt plants. The larvae recovered from Bt treatments weighed significantly less than those observed in the non-Bt isoline at 4 weeks after infestation. By the eighth week, the larval weights of all three treatments were similar in three of four different field tests, suggesting that second generation larvae have the ability to compensate for initial exposure to sublethal doses of Bt toxin. In laboratory assays involving exposure of neonate larvae to silks of Event 176 and non-Bt corn, survival of neonate $O$. nubilalis was not different although larval weights were significantly reduced (2- to 6-fold). These results suggest that second generation larvae completing development on Event 176 corn do not completely avoid exposure to the Bt toxin, although those that do survive are able to compensate for these sublethal effects. The implication of these results is that Event 176 hybrids do not appear to satisfy requirements for high dose that are recommended for resistance management purposes.
\end{abstract}

(C) 2002 Elsevier Science Ltd. All rights reserved.

Keywords: European corn borer; Bt corn; Resistance management

\section{Introduction}

Field tests using natural and manual European corn borer [Ostrinia nubilalis (Hübner)] infestations have shown that Bt corn hybrids provide more than $90 \%$ control of first generation larvae in whorl-stage corn (Barry and Darrah, 1997). However, the level of control against late-season $O$. nubilalis infestations differs among Bt corn events. Specifically, Event 176 hybrids express high levels of $\mathrm{Cry} 1 \mathrm{Ab}$ toxin in green plant tissue and pollen, but extremely low levels in the silk and

\footnotetext{
*Corresponding author. Tel.: + 1-402-472-8714; fax: + 1-402-4724687.

E-mail address: bsiegfried1@unl.edu (B.D. Siegfried).
}

kernels (Koziel et al., 1993). Additionally, this event is known to have reduced expression of the Bt toxin in green tissue as the plant senesces (Fearing et al., 1997; Ostlie et al., 1997). Second generation $O$. nubilalis larvae are known to infest the silks of developing ears, and have been shown to survive and later tunnel into the ears, ear shanks, and stalks of Event 176 corn (Siegfried et al., 2001). Larvae that complete development on Event 176 corn hybrids have therefore potentially survived a sublethal dose of the Bt toxin.

To ensure the long-term sustainability of Bt corn against $O$. nubilalis, management strategies that prevent or delay the development of resistance have been proposed. The high-dose/refuge strategy is the current foundation for managing pest resistance in Bt crops 
(Ostlie et al., 1997; International Life Sciences Institute, 1998; Andow and Hutchinson, 1998). This approach requires that the transgenic insecticidal crop kill all homozygous susceptible and most heterozygous individuals in the population, leaving very few heterozygous and rare homozygous resistant insects. A refuge of nonBt plants in close proximity to the Bt crop is intended to provide large numbers of homozygous susceptible insects to mate with any rare homozygous resistant insects that may survive on the transgenic crop (Alstad and Andow, 1995; Roush, 1996; Andow and Hutchison, 1998; Gould, 1998).

Because Event 176 hybrids have repeatedly been shown to support significant populations of second generation $O$. nubilalis, its ability to provide a high dose has been questioned (Onstad and Gould, 1998). Exposure to a potentially sublethal dose may result in increased selection for resistance because the titer of $\mathrm{Bt}$ within the plant is below a level necessary to kill heterozygous individuals that carry resistance alleles. Sublethal exposure is likely to be manifested in increased development times, reduced larval and pupal weights, and ultimately reduced reproductive fitness of adults (Tang et al., 1997). Alternatively, larvae that initiate feeding on Event 176 plants may exploit tissues that do not express toxins or possess levels that do not cause adverse effects such as silk, ears, and pith.

Siegfried et al. (2001) reported that $O$. nubilalis second generation larvae completing development on Event 176 hybrids in the field exhibited approximately $10 \%$ higher survival rates and correspondingly lower parasitism rates than larvae that developed on conventional corn hybrids. Furthermore, no significant differences in pupal weight, fecundity, longevity or susceptibility to the $\mathrm{Cry} 1 \mathrm{Ab} \mathrm{Bt}$ toxin were detected between larvae developing on Event 176 or the non-Bt isoline. These results indicate that survival on Event 176 corn does not adversely affect fitness and does not cause increased tolerance in subsequent generations. However, it is unclear whether these larvae avoided exposure to the toxin by exploiting tissues that do not express the toxin or whether initial sublethal exposure was compensated for later in larval development. The objective of the present study was to document the effect of Event 176 Bt transgenic corn on $O$. nubilalis larvae by comparing growth rates, survival and distribution among different plant structures of second generation larvae on Event 176 and its non-Bt isoline.

\section{Materials and methods}

\subsection{Field experiments}

The field experiments employed a randomized complete block design consisting of six replicated blocks of
Event 176 (Bt), detasseled Event 176 (Bt detasseled), and its non-Bt isoline. Each block was 8 rows wide $(76 \mathrm{~cm}$ between rows) by $4.6 \mathrm{~m}$ long and was planted within a large commercial field of non-Bt corn to achieve at least $30 \mathrm{~m}$ of separation between plots and to minimize $\mathrm{Bt}$ pollen movement between plots. Plots were located at two different sites: the University of Nebraska Agricultural Research and Development Center at Mead, Nebraska and at Iowa State University at Ames, Iowa in 1998 and 1999.

Fifteen plants from the second and fourth rows of the Event 176 plots were manually infested with approximately 50 neonate $O$. nubilalis larvae during early whorl stage and monitored for larval feeding to insure that the plants were expressing the Bt toxin. All infested plants were examined for larval injury after 1 week, and plants exhibiting signs of larval feeding were destroyed. Because Event 176 hybrids are known to express high levels of toxin during the whorl stage, non-expressing "off-types" could be identified by larval injury.

Plants were examined for egg masses of $O$. nubilalis before and during the experiment. However, natural populations of $O$. nubilalis were insignificant during both years of the study and at both sites (data not shown). Manual infestations of all treatments were timed to coincide with anthesis to ensure that pollen was present during the initial stages of larval development. Ten plants from each Bt plot known to be expressing Bt were then infested by pinning two individual blackhead stage $O$. nubilalis egg masses that had been oviposited onto waxed paper (supplied by the USDA-ARS Corn Insects and Crop Genetics Research Unit, Ames, IA) to the undersides of each of three leaves per plant; the ear leaf, second leaf above the ear, and the second leaf below the ear. Ten plants from the control plots containing the non- $\mathrm{Bt}$ isoline were infested in a similar manner.

Infested plants were dissected ( 2 plants per plot) at 1-, 2-, 4-, and 8-weeks after infestation to determine larval establishment and development. All parts of the corn plant including leaf midribs, leaf axils, husks, leaf sheaths, silks, ears, and stalks were examined for larval establishment. All plants were dissected in the field, and larvae collected from individual plants were placed in labeled $1.5-\mathrm{ml}$ centrifuge tubes and transported on ice to the laboratory to measure larval weight.

Differences among treatments within a given time period (weeks 1, 2, 4, and 8 post-infestation) were determined by analysis of variance (SAS Institute, 1999). Differences among treatment means were determined with the Fisher protected least significant difference (LSD) at the $5 \%$ level of significance (SAS Institute, 1999). For analysis of larval weights, each location and year were analyzed independently. For analysis of larval distribution among plant structures, 
data sets from each year and location were pooled to increase sample sizes.

\subsection{Silk bioassays}

Bioassays were performed with silk from Event 176 and non-Bt corn plants. Silk was obtained from Bt, Bt detasseled, and non-Bt isoline corn plants grown in a greenhouse in 1 gal pots at $30-35^{\circ} \mathrm{C}$ and $16: 8$ light:dark photoperiod. Ears from the Bt detasseled treatment were covered with plastic bags during anthesis to prevent pollination. In a separate experiment, silk was also obtained from a commercial field of Event 176 corn planted near Mead, Nebraska, USA. For the detasseled treatment, developing ears were again covered with plastic bags to prevent pollination. For the non-Bt treatment, silks were collected from a non-Bt hybrid of similar maturity growing within $1 \mathrm{~km}$ of the Event 176 field. During anthesis, ears were gathered from Bt, Bt detasseled, and non-Bt corn, transported on ice and refrigerated for up to 5 days. The silk was removed from the ears and placed lengthwise in plastic drinking straws to minimize desiccation. The silk filled straws were then cut into $2.5 \mathrm{~cm}$ lengths and placed in individual wells of 32 -well rearing trays (each well $25 \times 25 \mathrm{~mm}$ and $15 \mathrm{~mm}$ deep; Bioserv, Frenchtown, New Jersey). A single $O$. nubilalis neonate was placed in each well and the tray was sealed with contact paper that had been perforated with small holes for air exchange. The trays were then held in an incubator set at $37^{\circ} \mathrm{C}$ without lighting. Mortality and larval weight were recorded after 7 days.

Bioassays were repeated at least four times with 100 larvae tested per replicate. Differences in larval weight and mortality were determined by analysis of variance (SAS Institute, 1999). Differences between treatment means were assessed using the Fisher protected least significant difference (LSD) at the 5\% level of significance (SAS Institute, 1999).

\section{Results}

\subsection{Field experiments}

There were no significant differences observed between the weights of the larvae recovered from the non$\mathrm{Bt}$ isoline and those recovered from the Bt treatments 1 week after infestation in both years and at both locations (Figs. 1a-d). However by week 4, larvae recovered from the non-Bt isoline weighed significantly more than larvae from either of the two Bt treatments at both sites and during both years. There were no differences in larval weights between the Bt detasseled and $\mathrm{Bt}$ treatments in either year or at either location. Importantly, larvae recovered from Event 176 plants exhibited increased weight gain later in development (4-8 weeks) relative to the non-Bt isoline. By week 8 and in 3 of the 4 experiments, there were no significant differences in larval weights among any of the treatments

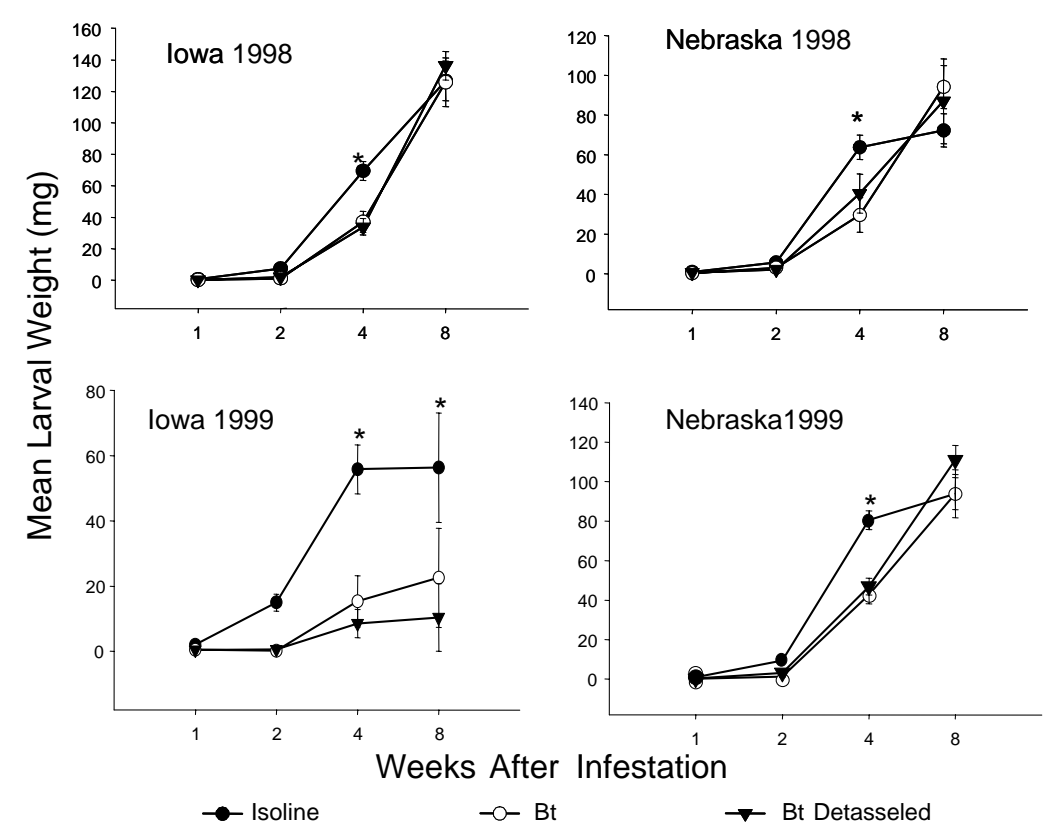

Fig. 1. O. nubilalis larval weights recorded at 1,2, 4, and 8 weeks after manual infestation of Event 176 plants (with and without tassels) and a non-Bt isoline. No significant differences were observed between Event 176 and Event 176 detasseled treatments. Significant differences $(P<0.05)$ between the non-Bt isoline and Bt treatments indicated by * (LSD test; SAS Institute Inc., 1999). Sample sizes varied among treatments and dates, but each point represents the mean of at least 5 individual larvae. 
in (Fig. 1). The only exception occurred in 1999 at the Iowa site where weights of larvae from the non-Bt isoline were significantly greater than the two $\mathrm{Bt}$ treatments at both weeks 4 and 8 (Fig. 1). However, it should be noted that larval weight of the control was considerably lower than the final weight achieved after four weeks in all the other experiments suggesting that overall development rates were delayed relative to the other experiments.

The distribution of $O$. nubilalis larvae from the various plant structures for combined data sets from Iowa and Nebraska and from both 1998 and 1999 are presented in Fig. 2. One week after infestation, larvae from the non-Bt treatment were concentrated in silk and leaf tissue. Larvae recovered from leaves were found feeding on pollen that had collected in the leaf axils. In contrast, larvae recovered from the $\mathrm{Bt}$ and $\mathrm{Bt}$ detasseled plants were found only in the silk and ear tips. The absence of larvae from leaves of Event 176 plants is not unexpected given the high expression of the Cry $1 \mathrm{Ab}$ toxin in green tissue and pollen. Significantly higher numbers of larvae were recovered from non-Bt isoline silk and ears suggesting some level of mortality was associated with feeding on reproductive tissue of the Event 176 plants or that mortality occurred from consumption of other plant tissue prior to reaching the silk and ears. Similar recovery rates between Event 176 plants with and without tassels suggest that the higher rates of survival on non-Bt plants is unrelated to the presence of high-expressing pollen that had fallen on silks.

Two weeks after infestation, the number of larvae recovered from silks had dropped considerably in all three treatments indicating that silk tissue was beginning to degrade and no longer provided a viable food source (Fig. 2). In contrast to the first week after infestation, there were few significant differences among treatments in larval numbers recovered from silk. Higher numbers

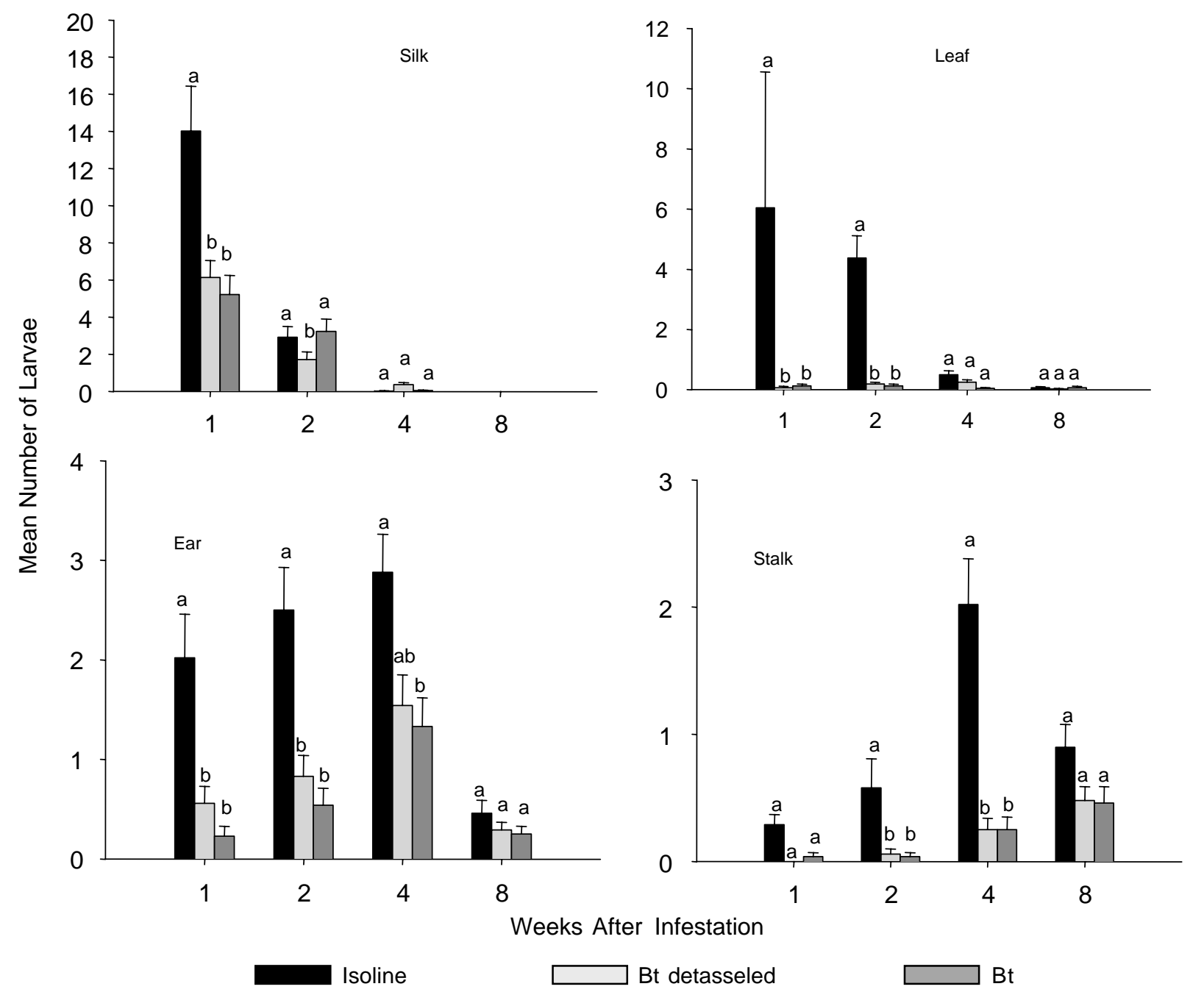

Fig. 2. Number of $O$. nubilalis larvae recovered from Event 176 corn plant tissues with and without tassels and from the non-Bt isoline. Bars indicate mean and SE for the total number of larvae recovered from each tissue type for the combined experiments from 1998 and 1999 and from Iowa and Nebraska. Bars with the same letter within a tissue and sampling date are not significantly different $(P<0.05 ;$ LSD test). 
of larvae were again recovered from leaves of the non- $\mathrm{Bt}$ plants compared to the two Bt treatments.

Numbers of larvae found in the ear were relatively constant from week 1 to week 4. However, it is likely that many larvae recovered from the silks during the first week could have easily moved to the ear tip. By weeks 2 and 4, the larvae were found boring into the ears, and numbers of larvae recovered from the ears of the non-Bt isoline were greater than those found in the two Bt treatments. Fewer larvae were found in the leaves, which corresponded to an increase in larvae recovered from the stalk.

By week 4, the stalks of the non-Bt isoline had significantly more larvae than either the $\mathrm{Bt}$ or $\mathrm{Bt}$ detasseled stalks. There was a gradual increase in the number of larvae found in the stalks from the two Bt treatments between weeks $2-8$. However, there was a large decrease in the number of larvae recovered in nonBt stalks between weeks $4-8$, such that by week 8 there were no longer any differences in the number of larvae recovered from stalks among the three treatments. Increased survival in the stalks of Bt plants is consistent with a general decline in Bt titer of Event 176 plants during senescence, and decreased sensitivity of later instar larvae (Huang et al., 1999).

\subsection{Silk bioassays}

Larvae reared on silks of the non-Bt isoline weighed significantly more than those reared on the silks of either of the Bt treatments (Table 1). When larvae developed on silk obtained from the greenhouse-grown corn, there was a significant difference between weights of larvae grown on Bt silk and those grown on Bt detasseled silk.

Table 1

Susceptibility of neonate $O$. nubilalis exposed for 7 days to fresh silks from Event 176 and non-Bt hybrids grown in the greenhouse or collected from the field

\begin{tabular}{|c|c|c|}
\hline \multirow[b]{3}{*}{ Treatment } & \multicolumn{2}{|l|}{ Silk source } \\
\hline & Greenhouse $^{\mathrm{a}}$ & Field $^{\mathrm{b}}$ \\
\hline & \multicolumn{2}{|c|}{ Larval weight \pm SE (mg) } \\
\hline Isoline & $12.29 \pm 0.47 \mathrm{a}$ & $9.61 \pm 0.46 \mathrm{a}$ \\
\hline $\mathrm{Bt}$ & $2.98 \pm 0.17 \mathrm{~b}$ & $3.96 \pm 0.24 \mathrm{c}$ \\
\hline \multirow[t]{2}{*}{ Bt detasseled } & $3.89 \pm 0.24 b$ & $4.00 \pm 0.26 \mathrm{~b}$ \\
\hline & \multicolumn{2}{|c|}{ Larval mortality \pm SE $(\%)$} \\
\hline Isoline & $18.0 \pm 10.5 \%$ a & $5.6 \pm 1.9 \%$ a \\
\hline $\mathrm{Bt}$ & $24.0 \pm 9.4 \% \mathrm{a}$ & $6.8 \pm 2.4 \%$ a \\
\hline Bt detasseled & $23.0 \pm 11.2 \% \mathrm{a}$ & $6.6 \pm 1.3 \%$ a \\
\hline
\end{tabular}

\footnotetext{
${ }^{\mathrm{a}} N=126,170,157$ for isoline, $\mathrm{Bt}$ and $\mathrm{Bt}$ detasseled treatments, respectively.

${ }^{\mathrm{b}} N=175,188,180$ for isoline, Bt and Bt detasseled treatments, respectively.

Means followed by the same letter within a column are not significantly different $(P<0.05$; LSD test) (SAS Institute, 1999).
}

However, when larvae developed on silk from fieldgrown plants, there was no significant difference between the $\mathrm{Bt}$ and $\mathrm{Bt}$ detasseled treatments (Table 1). There were no significant differences among any of the treatments in larval mortality.

\section{Discussion}

Event 176 plants clearly affected overall survival rates of $O$. nubilalis larvae. The silks, leaf axils, and ear tip of the non-Bt isoline supported more larvae than either of the $\mathrm{Bt}$ treatments during the first two weeks following infestation. This was especially true for larvae recovered from the leaf axil. Because Event 176 has high levels of $\mathrm{Bt}$ expression in pollen and green tissue, overall differences in establishment between Event 176 and the non-Bt isoline is at least partially attributable to the apparent preference of $O$. nubilalis neonates to initiate feeding on pollen collected in the leaf axils (Mason et al., 1996).

It is important to note that significant differences also were observed in the number of larvae recovered from reproductive tissues (i.e., silk and ear tips) that have been previously reported to express toxin at levels below the limits of detection (Koziel et al., 1993; Fearing et al., 1997). Such differences were not due to the presence of high-expressing pollen because the number of larvae recovered from detasseled plants was also significantly reduced relative to the isoline. However, it cannot be determined where these differences were due to direct mortality from feeding on reproductive tissue or if some mortality was caused by feeding prior to reaching the ears. The differences between Event 176 and isoline plants in the number of larvae recovered from reproductive tissue could be due prior feeding on green tissue or pollen.

Results from this investigation also indicate that sublethal exposure to the Bt toxin occurs among larvae developing on Event 176 plants based on reduced rate of weight gain of larvae that survived and developed on silk and ear tips. Furthermore, larvae that fed exclusively on silks of Event 176 corn from both intact and detasseled plants in laboratory assays weighed significantly less than those developing on non-Bt silk, although mortality was unaffected.

Previous work has shown that fitness parameters (e.g., pupal weight, adult longevity, and fecundity) of $O$. nubilalis completing development on Event 176 plants were not significantly affected (Siegfried et al., 2001). It was proposed that larvae completing development on these plants either compensated for sublethal exposure later in development or avoided exposure to the toxin by exploiting tissues that do not express the toxin. The present results suggest strongly that there is significant exposure to sublethal doses of the toxin that cause 
developmental delays in exposed larvae. However, these sublethal effects are compensated for by increased growth rates later in development. Therefore, significant fitness reductions would only be observed if the developmental delay were so severe that the larvae could not complete development before entering diapause. The significance of these findings in terms of resistance management and the high dose/refuge concept is that Event 176 does not appear to satisfy the high dose requirements for second generation larvae.

Although both the pollen and green tissue appear to satisfy the high dose criteria, the role of sublethal exposure that apparently occurs in reproductive tissue is difficult to assess as it does not appear to contribute directly to reduced survival. If the fitness of heterozyogous resistant individuals is significantly enhanced relative to susceptible homozyogotes because of sublethal expression of toxin, the high dose-refuge strategy would be severely compromised (Gould, 1998; International Life Sciences Institute, 1998). However, if expression of toxin is low enough to provide significant survival of susceptible homozygotes, the technology may still be utilized in a manner that is compatible with resistance management (Roush, 1996; Onstad et al., 2001).

\section{Acknowledgements}

The authors acknowledge the contributions of $\mathrm{M}$. Lavelle, C. King and S. Powell for assistance in field aspects of this work. T. Nowatzki and S. Parimi provided critical review of an earlier draft of this manuscript. Funding for this work was provided by Novartis Seeds Inc. and Mycogen Seeds Inc. This is journal series No. 13642 of the University of Nebraska Agricultural Experiment Station and contribution No. 1118 of the Department of Entomology.

\section{References}

Alstad, D.N., Andow, D.A., 1995. Managing the evolution of insect resistance to transgenic plants. Science 268, 1894-1896.

Andow, D.A., Hutchison, W.D., 1998. Bt corn resistance management. In: Mellon, M., Rissler, J. (Eds.), Now or Never: Serious New Plans to Save a Natural Pest Control. Union of Concerned Scientists, Cambridge, MA, pp. 19-66.
Barry, B.D., Darrah, L.L., 1997. European corn borer resistance: evaluation of commercial maize hybrids and transgenic maize cultivars. Proceedings of an International Symposium "Insect resistant maize: recent advances and utilization" held at the International Maize and Wheat Improvement Center, Mexico City, Mexico, pp. 266-270.

Fearing, P.L., Brown, D., Vlachos, D., Meghji, M., Privalle, L., 1997. Quantitative analysis of CryIA(b) expression in Bt maize plants, tissues, and silage and stability of expression over successive generations. Mol. Breeding 3, 169-176.

Gould, F., 1998. Sustainability of transgenic insecticidal cultivars: integrating pest genetics and ecology. Annu. Rev. Entomol. 43, 701-726.

Huang, F., Buschman, L.L., Higgins, R.A., 1999. Susceptibility of different instars of European corn borer (Lepidoptera: Crambidae) to diet containing Bacillus thuringiensis. J. Econ. Entomol. 92, $547-550$.

International Life Sciences Institute, 1998. An Evaluation of Insect Resistance Management in Bt Field Corn: A Science-Based Framework for Risk Assessment and Risk Management. ILSI Press, Washington, DC, 78pp.

Koziel, M.G., Beland, G.L., Bowman, C., Carozzi, N.B., Crenshaw, R., Crossland, L., Dawson, J., Desai, N., Hill, M., Kadwell, S., Launis, K., Lewis, K., Maddox, D., McPherson, K., Meghji, M.R., Merlin, E., Rhodes, R., Warren, G.W., Wright, M., Evola, S.V., 1993. Field performance of elite transgenic plants expressing an insecticidal protein derived from Bacillus thuringiensis. Bio/ Technology 11, 194-200.

Mason, C.E., Rice, M.E., Calvin, D.D., Van Duyn, J.W., Showers, W.B., Hutchison, W.D., Witkowski, J.F., Higgins, R.A., Onstad, D. W., Dively, G.P., 1996. European corn borer ecology and management. North Cent. Reg. Publ. 327, Iowa State University, Ames.

Onstad, D.W., Gould, F., 1998. Do dynamics of crop maturation and herbivorous insect life cycle influence the risk of adaptation to toxins in transgenic host plants? Environ. Entomol. 27, 517-522.

Onstad, D.W., Guse, C.A., Spencer, J.L., Levine, E., Gray, M.E., 2001. Modeling the dynamics of adaptation to transgenic corn by western corn rootworm (Coleoptera: Chrysomelidae). J. Econ. Entomol. 94, 529-540.

Ostlie, K.R., Hutchison, W.D., Hellmich, R.L., 1997. Bt corn and European corn borer. NCR Publication 602, University of Minnesota, St. Paul, MN.

Roush, R.T., 1996. Can we slow adaptation by pests to insect resistant transgenic crops. In: Persley, G.J. (Ed.), Biotechnology and Integrated Pest Management. University Press, Cambridge, England, pp. 242-263.

SAS Institute, 1999. SAS version 8.01. SAS Institute, Cary, NC, $441 \mathrm{pp}$.

Siegfried, B.D., Zoerb, A., Spencer, T., 2001. Effect of Event 176 transgenic maize on susceptibility and fitness of the European corn borer. Entomol. Exp. Appl. 100, 15-20.

Tang, J.D., Gilboa, S., Roush, R.T., Shelton, A.M., 1997. Inheritance, stability, and lack-of-fitness costs of field-selected resistance to Bacillus thuringiensis in diamondback moth (Lepidoptera: Plutellidae) from Florida. J. Econ. Entomol. 90, 732-741. 